\title{
Contralateral approaches to bilateral cerebral aneurysms: a microsurgical anatomical study
}

\author{
Eric M. Oshiro, M.D., David A. Rini, M.F.A., and Rafael J. Tamargo, M.D.
}

Department of Neurosurgery, The Johns Hopkins Hospital, Baltimore, Maryland

In patients with bilateral supratentorial aneurysms, surgical clipping of all aneurysms via a unilateral approach would obviate the need for a second operation. The authors conducted a microsurgical study in human cadaver heads to examine the contralateral exposure for four common aneurysm sites in the anterior circulation: the ophthalmic artery (OA) origin, the posterior communicating artery (PCoA) origin, the internal carotid artery (ICA) termination, and the middle cerebral artery (MCA) bifurcation. Frontotemporal craniotomies were performed in 16 cadavers to evaluate the corridor for exposure of these sites from the contralateral side. Morphometric data, including lengths and diameters of major arterial segments and optic nerves, were documented for anatomical correlation.

In this study, the contralateral OA origin was successfully exposed in $62 \%$ of specimens, the PCoA origin in $50 \%$, the ICA bifurcation in 100\%, and the MCA bifurcation in $62 \%$. Exposure of the OA origin and, in some cases, the PCoA, required incision of the falciform ligament and mobilization of the contralateral optic nerve. Exposure of the MCA bifurcation was dependent on the length of the $\mathrm{M}_{1}$ segment, with successful exposure only when this segment was shorter than $14 \mathrm{~mm}$. Implications for the contralateral approach to aneurysms at these sites are discussed and the microsurgical corridors for exposure are described.

For correlation with the anatomical study, a brief clinical review of patients with bilateral supratentorial aneurysms treated at The Johns Hopkins Hospital between 1992 and 1995 is presented. Guidelines for the contralateral approach to aneurysms are discussed with reference to the anatomical study and the clinical review.

Key Words * cerebral aneurysm * bilateral supratentorial aneurysm * contralateral approach * microsurgery * anatomical study

Among patients diagnosed with cerebral aneurysms, the reported incidence of multiple intracranial aneurysms is between $14 \%$ and 34\%.[11] In approximately 20 to $40 \%$ of these patients, the aneurysms are bilateral.[6,11] Given the actuarial risk of rupture, the surgical goal in patients with bilateral aneurysms is clipping of all lesions. This goal has traditionally been accomplished via sequential craniotomies, starting with the side of the ruptured aneurysm. Ideally, if the contralateral vascular anatomy were exposed adequately and safely, surgical clipping of all aneurysms via a single, unilateral craniotomy would simplify treatment because it would obviate the need for a second operation. 
Although published case reports and small series have described contralateral frontotemporal approaches to supratentorial aneurysms, the guidelines for the surgical exposure and clipping of contralateral aneurysms have not been well established. We conducted a microsurgical anatomical study in cadaver specimens to examine the contralateral exposure of four of the most common sites for aneurysms in the anterior circulation: the origin of the ophthalmic artery (OA), the origin of the posterior communicating artery (PCoA), the internal carotid artery (ICA) termination, and the middle cerebral artery (MCA) bifurcation. The anterior communicating artery complex, as a midline structure, was not considered in our study because it is assumed to be equally accessible from either side. We have attempted to establish guidelines for the microsurgical exposure of aneurysms at these sites based on morphometric data obtained in our study.

In addition, we conducted a brief review of patients with bilateral supratentorial aneurysms treated at our institution between 1992 and 1995 to illustrate the influence of both anatomical and clinical features on successful contralateral exposure. Treatment for these patients presenting with bilateral aneurysms was based on individual anatomy and the clinical setting and included contralateral approaches, sequential unilateral craniotomies, and unilateral craniotomies treating only the symptomatic side.

\section{CLINICAL MATERIAL AND METHODS}

\section{Microsurgical Anatomical Studies}

Frontotemporal craniotomies were performed in 16 adult cadaveric heads, of which 10 had been fixed in formalin and six were fresh specimens treated with vascular silicone injections. All anatomical specimens for this study were provided by the Maryland State Anatomy Board. Fresh specimens were chosen for comparison in the latter half of the study to assure that retraction and exposure were not altered by the fixation process. For vascular-injected specimens, the common carotid arteries and internal jugular veins were isolated in the neck, perfused with saline, and injected with red or blue silicone (Bio-Dur S-10, with S-3 hardener and S-6 curing agent, Bio-Dur color paste; Von Hagens, Heidelberg, Germany). A curvilinear skin incision was made from the zygomatic arch $1 \mathrm{~cm}$ anterior to the tragus and extending to the midline behind the hairline, and the skin flap and temporalis muscle were retracted anteriorly. A frontotemporal bone flap was made using a perforator and craniotome. This bone flap was fashioned using four burr holes as described by Yasargil[15] and Fox.[1] The craniotome was used to connect the burr holes, with extension medially along the orbital rim, to create a craniotomy with low exposure of the frontal and middle fossae. The lateral aspect of the lesser wing of the sphenoid was removed using a drill and rongeurs. A semicircular dural incision was made centered on the sphenoid ridge and reflected anteriorly.

Dissection of the arterial anatomy was then performed with the aid of an operating microscope. After opening the ipsilateral sylvian fissure widely to facilitate retraction of the frontal lobe, the ipsilateral optic nerve, supraclinoid carotid artery (CA), PCoA, first segments of the middle and anterior cerebral arteries, and basilar apex were identified using gentle frontal and temporal lobe retraction. Exposure of the contralateral OA origin, take-off of the PCoA, ICA termination, and MCA bifurcation was then attempted. Mobilization of the contralateral optic nerve by incision of the falciform dural fold was performed to enhance exposure of the OA and PCoA. Lengths and diameters of the major contralateral arterial segments and lengths of the optic nerves were documented.

Table 1 summarizes the morphometric measurements obtained in the microsurgical anatomical study. Measurements and successful exposure of contralateral anatomical sites did not differ significantly 
between formalin-fixed and fresh specimens.

\begin{tabular}{|c|c|c|c|c|}
\hline \multicolumn{5}{|c|}{$\begin{array}{c}\text { TABLE } 1 \\
\text { SUMMAR OF WOR PHOMETRIC MEASUREMENTS OBTANED FROMA } \\
\text { MICROSURGCALANATOMK SL STUDV OF CONTRALATERAL EXPOSURE } \\
\text { IN TG CADAVER HEADS }\end{array}$} \\
\hline Contralateral Anatomy & $\begin{array}{c}\text { No. of } \\
\text { Specimers }\end{array}$ & $\begin{array}{l}\text { Rarnge } \\
(\mathrm{m} m)\end{array}$ & $\begin{array}{l}\text { Wean } \\
(\mathrm{mm})\end{array}$ & $\begin{array}{l}\text { Medan } \\
(\mathrm{mm})\end{array}$ \\
\hline optic nerve length & 16 & $6.0-14.5$ & 9.9 & 10.0 \\
\hline $\begin{array}{l}\text { falciform ligament width (largest } \\
\text { dimension) }\end{array}$ & 12 & $1.0-6.0$ & 2.9 & 3.0 \\
\hline ICA diameter (at ICA tifurcation) & 15 & $3.2-5.2$ & 4.4 & 4.6 \\
\hline$M_{1}$ diameter (at ICA bifurcation) & 16 & $3.2-4.8$ & 3.8 & 3.8 \\
\hline $\mathrm{A}_{1}$ diameter (at ICA bifurcation) & 16 & $2.0-3.2$ & 2.8 & 3.0 \\
\hline POOÁ diameter & 11 & $0.8-3.8$ & 1.7 & 1.8 \\
\hline AChÁ diameter & 10 & $0.5-1.2$ & 0.9 & 1.0 \\
\hline supradinoid ICA length & 15 & $8.0-19.0$ & 13.8 & 14.0 \\
\hline$M_{1}$ length & 16 & $7.0-26.0$ & 13.5 & 13.0 \\
\hline$A_{1}$ length & 14 & $7.0-18.0$ & 11.8 & 12.0 \\
\hline length of OA exposed & 8 & $1.0-7.0$ & 3.3 & 3.0 \\
\hline
\end{tabular}

\section{Technical Notes: Contralateral Exposure}

Step 1: Ipsilateral Exposure. Exposure was maximized by a low frontoorbital extension of the standard frontotemporal craniotomy to facilitate frontal lobe retraction. The lesser wing of the sphenoid and bone irregularities of the lateral frontal floor were reduced with a high-speed drill to provide low exposure of the frontal and middle fossae. As with a standard unilateral exposure, the ipsilateral optic nerve and CA were first identified and the carotid and optic cisterns opened widely with sharp dissection of the arachnoid, exposing the optic nerve as far back as the chiasm and the CA up to the bifurcation. Contralateral exposure was initiated by releasing the adhesions along the ipsilateral $\mathrm{A}_{1}$ segment, exposing the lamina terminalis and proceeding anteriorly along the contralateral optic nerve to its exit under the falciform dural fold. Perforation of the lamina terminalis and evacuation of cerebrospinal fluid (CSF) from the ventricle is always performed at this point to facilitate retraction, even if lumbar drainage of CSF has already been initiated. The contralateral $\mathrm{A}_{1}$ segment was identified and the exposure broadened by dissection proximally between the $\mathrm{A}_{1}$ segment and the chiasm to reach the contralateral opticocarotid space.

Step 2: Exploration of the Interoptic Space. The interoptic space (Fig. 1) provides the microsurgical corridor for exposure of the origins of the contralateral OA and PCoA. Exploration of the interoptic space was preceded by incision of the falciform dural ligament from a medial to lateral direction along the bony edge of the optic canal (Fig. 2 left). This maneuver unroofed the distal intracranial portion of the optic nerve an additional 1 to $5 \mathrm{~mm}$, allowing safer and better retraction of the optic nerve. Dissection of adhesions along the inferior surface of the contralateral optic nerve exposed the medial surface of the contralateral supraclinoid carotid segment (Fig. 2 right). Gentle retraction of the optic nerve laterally exposed the origin of the contralateral $\mathrm{OA}$ in those cases in which it originated from the medial surface of the CA (Fig. 3 upper left). Continuing the dissection along the medial surface of the CA in the interoptic space brought into view the origin of the contralateral PCoA (Fig. 3 upper right). 


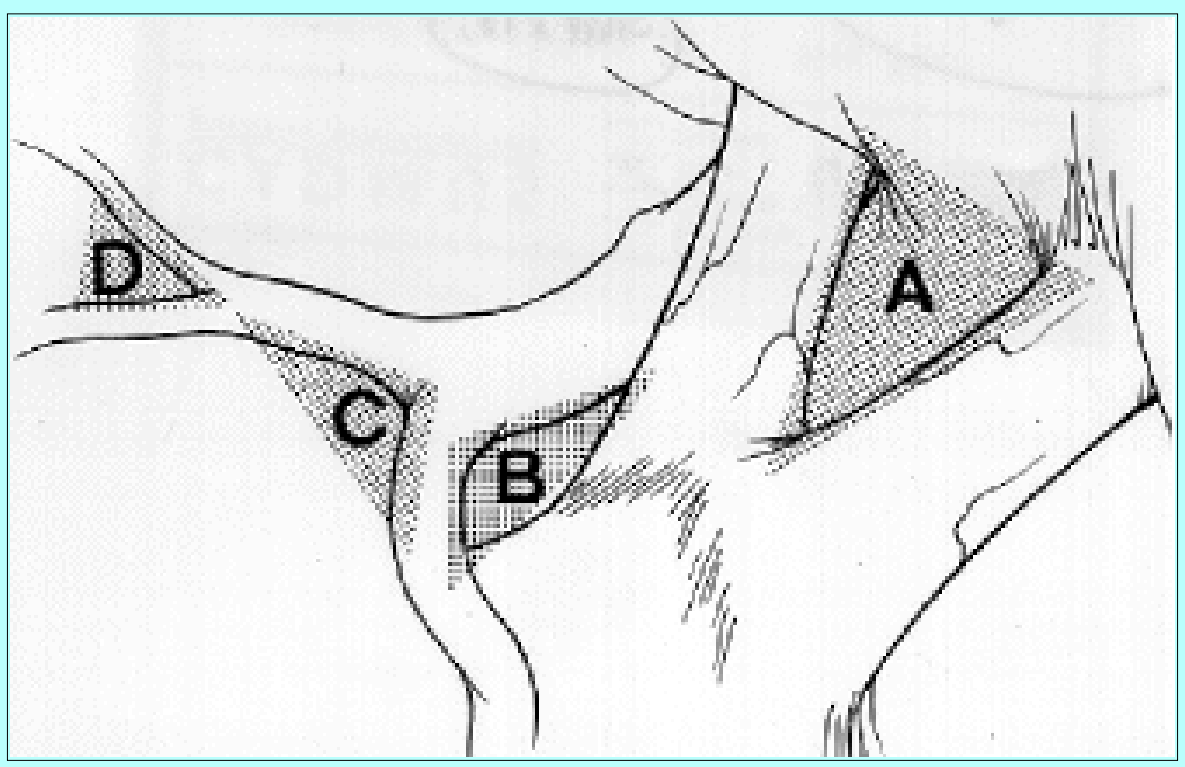

Fig. 1. Drawing showing corridors for exposure of contralateral aneurysms represented as anatomical triangles. A: The interoptic space. B: The opticocarotid space. C: The supracarotid space. D: The MCA triangle.

Step 3: Exploration of the Contralateral Opticocarotid Space. The medial surface of the contralateral distal CA was explored superior and lateral to the optic chiasm with lateral retraction of the CA. The borders of the lateral margin of the contralateral optic nerve and tract, the optic chiasm, the inferior surface of the contralateral $\mathrm{A}_{1}$ segment, and the medial surface of the contralateral distal CA defined the opticocarotid space (Fig. 1). The medial surface of the contralateral distal CA, including the anterior choroidal artery (AChA), was explored via this microsurgical corridor. Occasionally, the PCoA will be viewed through this corridor, in the case of a long supraclinoid CA segment in association with a prefixed chiasm or a distal origin of the PCoA.

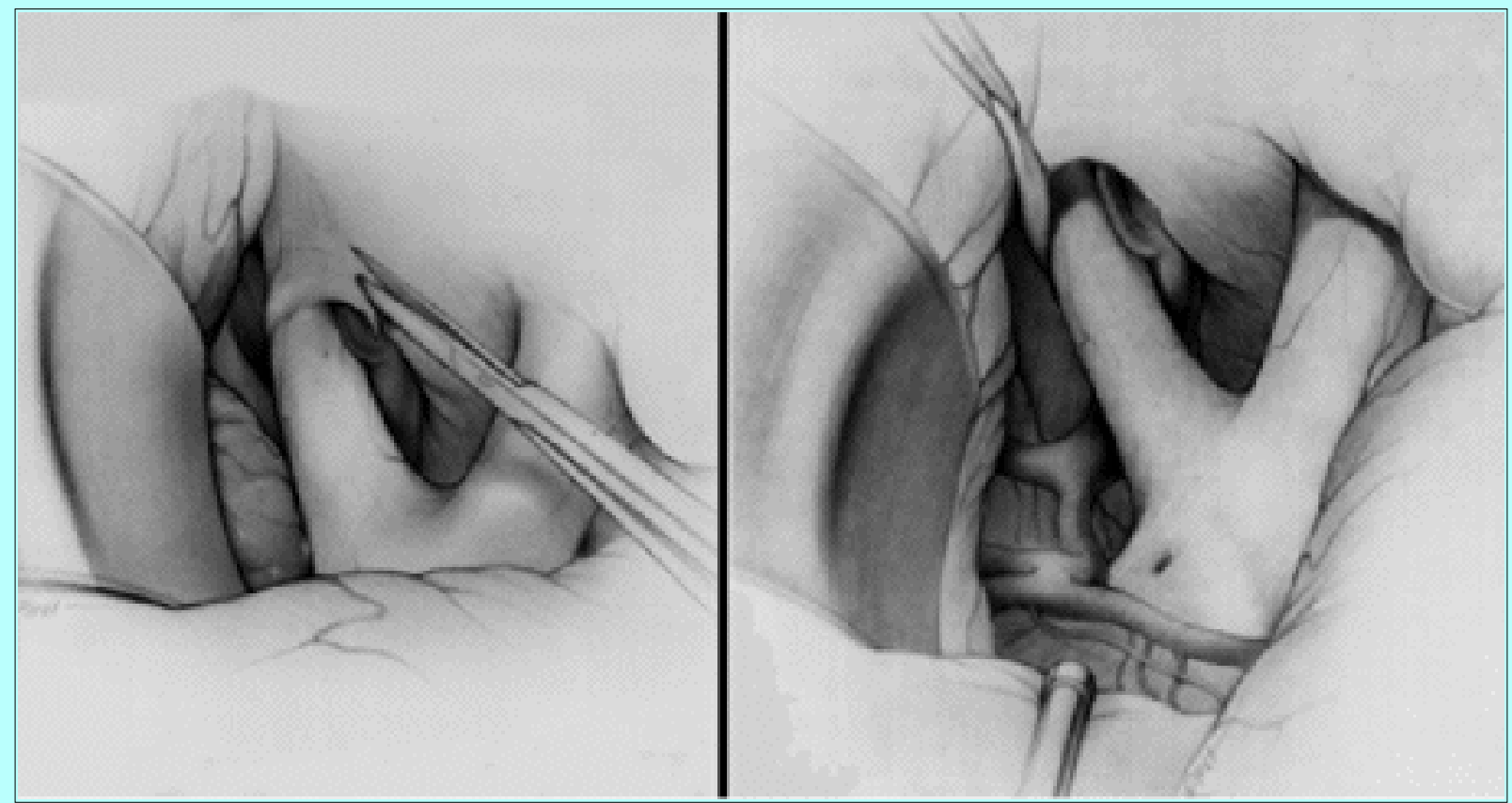

Fig. 2. Drawings showing technical aspects of contralateral exposure. Left: Incision of the falciform dural fold overlying the contralateral optic nerve allows greater exposure of the medial surface of the supraclinoid CA and safer retraction of the optic nerve. Right: Frontal 
lobe retraction, aided by cisternal CSF drainage and lamina terminalis perforation, and completed incision of the falciform dural fold allow for exposure of the contralateral OA origin, medial surface of the supraclinoid CA, and ICA termination.

\section{Step 4: Exposure of the Contralateral ICA Termination in the Supracarotid Space. The} contralateral CA segment lateral to the chiasm was identified and the dissection carried distally. Alternatively, dissection of the contralateral $\mathrm{A}_{1}$ segment proximally along its inferior surface over the optic chiasm will provide a safe corridor for the progressive exposure of the carotid termination. The borders of the superior surfaces of the proximal $M_{1}$ and $A_{1}$ segments and the retracted surface of the basomedial frontal lobe defined the contralateral supracarotid space (Fig. 1). Progressive elevation of the medial frontal lobe led to identification of the carotid termination and the origin of the contralateral $\mathrm{M}_{1}$ segment (Fig. 3 lower left).

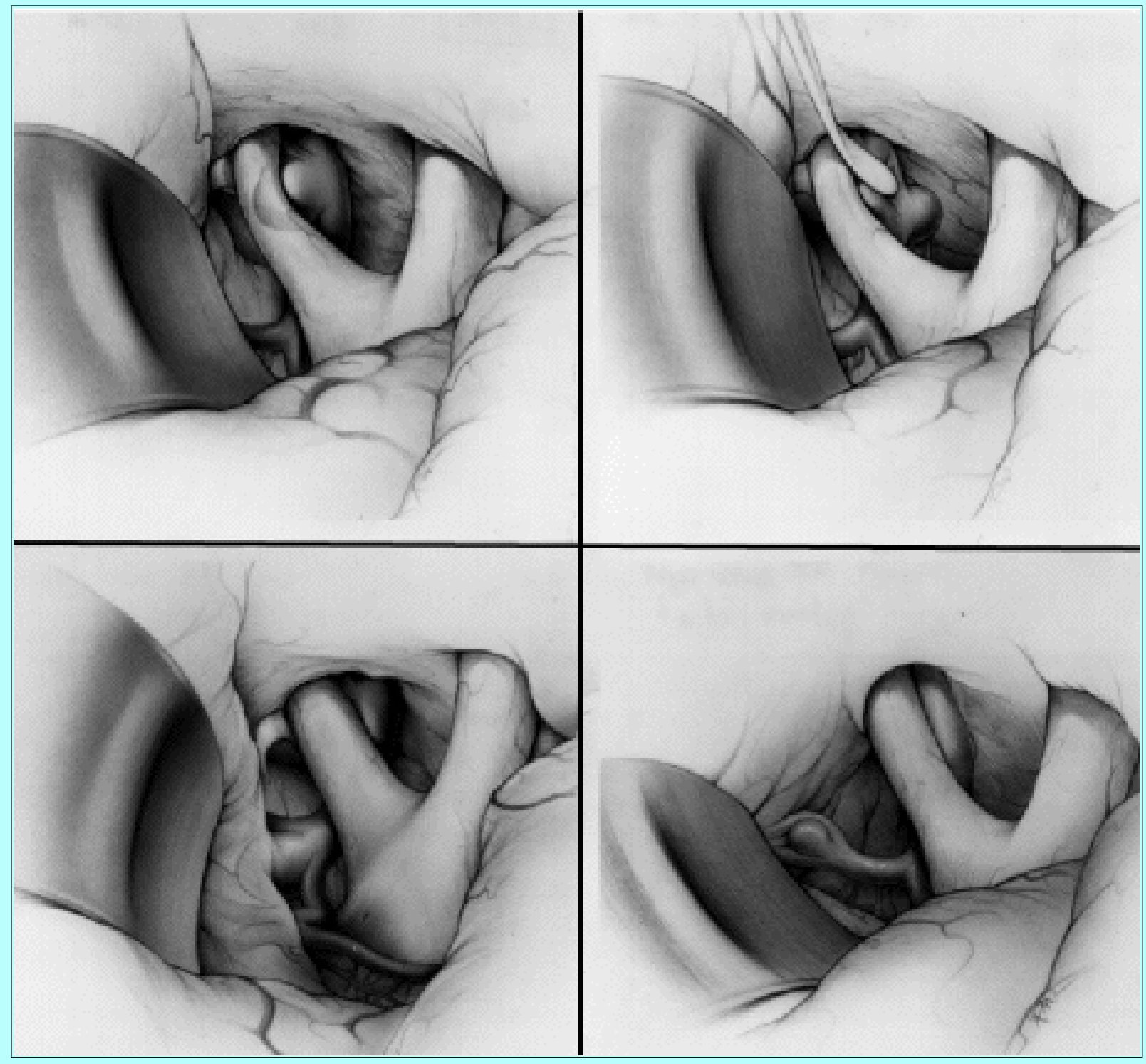

Fig. 3. Drawings depicting anterior circulation aneurysms exposed via a contralateral frontotemporal craniotomy. Upper Left: The OA aneurysm exposed after incision of the falciform dural fold. Upper Right: The PCoA aneurysm exposed via the interoptic space. Lower Left: The ICA termination aneurysm exposed in the supracarotid space. Lower Right: The MCA bifurcation aneurysm exposed in the contralateral MCA triangle. 
Step 5: Exposure of the Contralateral MCA Bifurcation. Dissection along the proximal $\mathrm{M}_{1}$ segment distally required progressively increased retraction of the contralateral frontal lobe. Dissection of the arachnoid adhesions along the $\mathrm{M}_{1}$ segment within the proximal sylvian cistern resulted in progressive separation of the contralateral frontal and temporal lobes, increasing retraction and exposure. Continuing the dissection primarily along the inferior surface of the MCA reduced the risk of injury to the lenticulostriate arteries. Progressive opening of the sylvian cistern and frontal lobe retraction then led to exposure of the contralateral MCA bifurcation (Figs. 1 and 3 lower right).

\section{Clinical Review}

Between 1992 and 1995, 289 consecutive patients were admitted to the Johns Hopkins Hospital or the Johns Hopkins Bayview Medical Center with the diagnosis of angiographically confirmed cerebral aneurysms. Each patient was treated by one of five different staff members. In this series, 53 patients (18.3\%) were found to have multiple supratentorial aneurysms, and $23(8 \%)$ of the 289 patients had bilateral supratentorial aneurysms. A contralateral approach was attempted in nine of the 23 patients. In another nine of these patients, either on the same day or at different settings, bilateral craniotomies were performed because of the complexity of the vascular anatomy as judged by the attending surgeon. Of the remaining patients, four underwent a unilateral craniotomy for treatment of the symptomatic lesion, with plans to treat the lesions on the contralateral side based on the patients' clinical condition, and in one patient who harbored bilateral mycotic aneurysms, surgery was not performed pending medical management with antibiotic drugs and follow-up angiograms.

Of the nine patients in whom contralateral craniotomies were attempted, contralateral aneurysms were successfully clipped in six of them, including four PCoA aneurysms, one OA aneurysm, and one ICA termination aneurysm. In one patient, exploration of the contralateral PCoA origin revealed an infundibulum that did not require clipping. In the remaining two patients, the contralateral exploration was unsuccessful, with the attempt aborted secondary to brain swelling related to acute subarachnoid hemorrhage (SAH). A summary of the 23 patients with bilateral supratentorial aneurysms, listed by date of admission, is presented in Table 2. 
TABLE 2

SUMMARY OF CL NICAL CHARACTER ISTICS AND TREATMENT IN 23 PATIENTS WITH BILATERAL SUPRATENTORIAL ANEURVSMS*

\begin{tabular}{|c|c|c|c|c|c|c|}
\hline \multirow{2}{*}{$\begin{array}{l}\text { Case } \\
\text { No. }\end{array}$} & \multirow{2}{*}{$\begin{array}{l}\text { Presen- } \\
\text { tation }\end{array}$} & \multirow{2}{*}{$\begin{array}{c}\text { Hurk \& } \\
\text { Hess } \\
\text { Grade }\end{array}$} & \multicolumn{2}{|c|}{ Aneurysm Site } & \multirow[b]{2}{*}{ Treatment } & \multirow[b]{2}{*}{ Comments } \\
\hline & & & $\mathrm{Rt}$ & Lt & & \\
\hline 1 & $\mathrm{SAH}$ & III & $\mathrm{MCA}$ & $\mathrm{PCOA}$ & CAp, rt side & $\begin{array}{l}\text { successid, all aneurysms } \\
\text { clipped }\end{array}$ \\
\hline 2 & $\begin{array}{l}\text { urrup- } \\
\text { tur ed }\end{array}$ & 0 & $\mathrm{MCA}$ & $O A, A C O A$ & $\mathrm{BiCr}, 1$ op & $\begin{array}{l}\text { CAp not attenpted, com- } \\
\text { plex vascular anatomy }\end{array}$ \\
\hline 3 & $S A H$ & 0 & $\operatorname{MCA}(3]$ & $\mathrm{MCA}, \mathrm{PCOA}$ & BiCr, 1 op & $\begin{array}{l}\text { CAp not attempted, com- } \\
\text { plex vascular anatomy }\end{array}$ \\
\hline 4 & $\mathrm{SAH}$ & II & $\mathrm{PC} 0 A$ & $O A$ & $\mathrm{BiCr}, 2$ ops & $\begin{array}{l}\text { CAp not attempted, com- } \\
\text { plex vascular anatomy }\end{array}$ \\
\hline 5 & $\mathrm{~S} A \mathrm{H}$ & 1 & $\mathrm{MCA}$ & $M(C A(2)$ & $\mathrm{BiCr}, 2$ ops & $\begin{array}{l}\text { CAp not attempted, com- } \\
\text { plex vascular anatomy }\end{array}$ \\
\hline 6 & $\mathrm{~S} A \mathrm{H}$ & III & PCOA & $\mathrm{PC} 0 A$ & CAp, rt side & $\begin{array}{l}\text { negative exploration, } \\
\text { It } \mathrm{PC} \text { C Airf undibutum }\end{array}$ \\
\hline 7 & $\mathrm{~S} A \mathrm{H}$ & I & $\mathrm{PCOA}$ & $\begin{array}{l}\text { ICAterm, } \\
\text { sup hyp }\end{array}$ & CAp, It si de & $\begin{array}{l}\text { successfu, all aneurysms } \\
\text { clipped }\end{array}$ \\
\hline 8 & $\begin{array}{l}\text { urrup- } \\
\text { tur ed }\end{array}$ & 0 & $\begin{array}{l}\mathrm{MCA} I C A \\
\text { term } \mathrm{M}_{1}\end{array}$ & $\begin{array}{l}\mathrm{MCA} I C A \\
\text { term }\end{array}$ & $\begin{array}{l}\mathrm{BiCr}, 2 \text { ops } \\
\text { term }\end{array}$ & $\begin{array}{l}\text { CAp not attempted, com- } \\
\text { plex vascular anatomy }\end{array}$ \\
\hline 9 & $\mathrm{~S} \wedge \mathrm{H}$ & II & $\mathrm{PCOA}$ & $\mathrm{MCA}$ & $\mathrm{BiCr}, 2$ ops & $\begin{array}{l}\text { CAp not attempted, com- } \\
\text { plex vascular anatomy }\end{array}$ \\
\hline 10 & $\mathrm{SAH}$ & 1 & $\begin{array}{l}\mathrm{PC} 0 A \\
\mathrm{MCA}\end{array}$ & $\mathrm{PC} 0 A, \mathrm{MCA}$ & $\mathrm{BiCr}, 2$ ops & $\begin{array}{l}\text { CAp not attempted, com- } \\
\text { plex vascular anatomy }\end{array}$ \\
\hline 11 & $\begin{array}{l}\mathrm{S} A \mathrm{H} \\
\mathrm{ICH}\end{array}$ & I & $\begin{array}{l}\mathrm{MCA} \\
\mathrm{OA}\end{array}$ & $O A$ & no surgery & $\begin{array}{l}\text { suspected mycolic } \\
\text { aneurysms }\end{array}$ \\
\hline 12 & $\begin{array}{l}\text { urrup- } \\
\text { tư ed }\end{array}$ & 0 & $\mathrm{PCOA}$ & $\mathrm{MCA}, \mathrm{PCOA}$ & Cr, it side orly & $\begin{array}{l}\text { CAp not attempted, com- } \\
\text { plex vascular anatomy }\end{array}$ \\
\hline 13 & $\begin{array}{l}\text { urrup- } \\
\text { tur ed }\end{array}$ & 0 & $\mathrm{MCA}$ & $\mathrm{MCA}$ & Cr, it side orly & $\begin{array}{l}\text { left MCA aneurym to be } \\
\text { followed }\end{array}$ \\
\hline 14 & $\mathrm{~S} A \mathrm{H}$ & I & PCaA & ICAterm & $\mathrm{BiCr}, 1$ op & $\begin{array}{l}\text { CAp not attempted, } \\
\text { brain s'welling }\end{array}$ \\
\hline 15 & $\mathrm{~S}, \mathrm{AH}$ & III & $\mathrm{PC} 0 A$ & $P C O A$ & CAp, It si de & CAp aborted, brain swelling \\
\hline 16 & $\mathrm{SAH}$ & I & $\mathrm{PC} 0 \mathrm{~A}$ & $\mathrm{PCOA}$ & CAp, rt side & CAp aborte d, brain swelling \\
\hline 17 & $\mathrm{SAH}$ & II & $\begin{array}{l}\mathrm{PCOA} \\
\mathrm{MCA}\end{array}$ & $O A$ & CAp, rt side & $\begin{array}{l}\text { successid, all aneurysms } \\
\text { clipped }\end{array}$ \\
\hline 18 & urrup- & 0 & $\begin{array}{l}\text { MCA } \\
\text { ICAterm }\end{array}$ & ICAterm & CAp, rt side & $\begin{array}{l}\text { successfu, all aneurysms } \\
\text { clipped }\end{array}$ \\
\hline 19 & $\begin{array}{l}\text { urrup- } \\
\text { tur ed }\end{array}$ & 0 & PCaA & $\mathrm{PCOA}$ & CAp, rt side & $\begin{array}{l}\text { successid, al aneurysms } \\
\text { clipped }\end{array}$ \\
\hline 20 & $\begin{array}{l}\text { urrup- } \\
\text { tur ed }\end{array}$ & 0 & $O A$ & $\mathrm{MCA}$ & Cr, it side orly & $\begin{array}{l}\text { small it MCA ane urym to } \\
\text { be followed }\end{array}$ \\
\hline 21 & $S A H$ & III & $\begin{array}{l}\mathrm{PCOA} \\
\mathrm{MCA}\end{array}$ & $P C a A, M_{1}$ & $\mathrm{BiCr}, 2$ ops & $\begin{array}{l}\text { CAp not attempted, com- } \\
\text { plexvascuar anatomy }\end{array}$ \\
\hline 22 & $\mathrm{~S}, \mathrm{AH}$ & 1 & $\mathrm{PC} 0 \mathrm{~A}$ & $\mathrm{PCOA}$ & CAp, rt side & $\begin{array}{l}\text { successitd, all aneurysms } \\
\text { clipped }\end{array}$ \\
\hline 23 & $\mathrm{SAH}$ & 1 & $\mathrm{PCaA}$ & $\mathrm{MCA}$ & Cr, it side orly & $\begin{array}{l}\text { CAp not attempted, com- } \\
\text { plex vascular anatomy }\end{array}$ \\
\hline
\end{tabular}

${ }^{\mathrm{ACOA}}=$ anterior communicating artery, $\mathrm{BCO} 1 \mathrm{op}=$ tilateral craniotomy in one operating room session; $\mathrm{BC} 2 \mathrm{op}=$ tilateral cranio tom $\mathrm{y}$ in two separate operating room sessions; CAp = contralateral approach; $\alpha=$ unilateral craniotom $y, 1 \mathrm{CA}$ term = ICA termination; $\mathrm{ICH}=$ intracerebral hemorhage; sup hyp = superior hypophyseal artery

\section{RESULTS}

\section{Exposure of the Origin of the Contralateral $\mathrm{OA}$}

The origin of the contralateral OA was successfully exposed in $10(62 \%)$ of 16 specimens. The optimum 
corridor for visualization of this vessel was always the interoptic space below the optic nerve. Exposure was optimized by incision of the falciform dural fold and partial mobilization of the contralateral optic nerve. The contralateral OA always originated from the medial aspect of the ICA in the dissections in which it was successfully exposed. In these specimens, the length of the OA ranged from 1 to $7 \mathrm{~mm}$ (mean $3.3 \mathrm{~mm}$ ). Exposure of the contralateral OA origin was not dependent on any of the measured anatomical parameters, such as optic nerve length or the length of the supraclinoid ICA segment.

\section{Exposure of the Origin of the Contralateral PCoA}

The origin of the PCoA from the contralateral ICA was successfully exposed in eight (50\%) of 16 specimens. The corridor for visualization of the contralateral PCoA usually ran through the interoptic space, occasionally requiring incision of the falciform dural ligament and mobilization of the contralateral optic nerve. The medial aspect of the PCoA origin can be viewed through this corridor. In one specimen, however, the PCoA origin was not visualized via the interoptic space, but was adequately exposed through the opticocarotid corridor, superior and lateral to the optic chiasm. Visualization of the contralateral PCoA origin did not correlate with the presence of a prefixed optic chiasm, as determined by the length of the optic nerve from falciform ligament to chiasm, or with the length of the supraclinoid CA segment from the dural ring to the origin of the PCoA. The origin of the AChA was adequately exposed via the opticocarotid corridor, superior and lateral to the optic chiasm, by means of lateral retraction of the supraclinoid CA segment in seven (44\%) of 16 cases.

\section{Exposure of the Contralateral ICA Termination}

The ICA termination was successfully exposed immediately above the lateral aspect of the optic chiasm in all specimens examined. Visualization of the distal ICA and proximal $\mathrm{A}_{1}$ and $\mathrm{M}_{1}$ segments was universally achieved with only moderate retraction of the frontal lobes.

\section{Exposure of the Contralateral MCA Bifurcation}

Exposure of the contralateral MCA bifurcation was possible in $10(62 \%)$ of 16 cadaver specimens, with significant retraction of both frontal lobes. Visualization of the contralateral MCA bifurcation was correlated to the length of the contralateral $\mathrm{M}_{1}$ segment. In our study, the $\mathrm{M}_{1}$ segment ranged from 7 to $26 \mathrm{~mm}$ in length (mean $13.5 \mathrm{~mm}$ ). The contralateral MCA bifurcation was visualized in all specimens with $\mathrm{M}_{1}$ segments less than $14 \mathrm{~mm}$ in length, but could not be exposed using reasonable retraction if the $\mathrm{M}_{1}$ segment was longer than $14 \mathrm{~mm}$.

\section{DISCUSSION}

The ideal surgical treatment in patients with multiple intracranial aneurysms is clipping of all lesions. In patients harboring bilateral supratentorial aneurysms, a contralateral approach to these lesions, assuming that the exposure of the contralateral aneurysms could be achieved adequately and safely, might reduce the overall rates of morbidity and mortality and the cost of treatment, because the patient could avoid a second craniotomy and anesthesia.

Although the contralateral frontotemporal approach to anterior circulation aneurysms has been described in previous studies, clear guidelines with respect to microsurgical anatomical corridors of approach have not been established. Nakao, et al.,[8] Milenkovic, et al.,[7] Nishio, et al.,[9] and Yamada, et al.,[14] have described the contralateral surgical approach to obliterate medially projecting OA aneurysms. 
Yasargil,[16] Vajda, et al.,[13] and Lynch and Andrade[6] have published small series describing the contralateral frontotemporal approach to aneurysms involving the medial surface of the ICA, the CA termination, and the MCA bifurcation. Although Vajda, et al.,[13] reported successful clipping of 41 of 43 contralateral aneurysms in 39 patients, they did not document the distribution of the locations of the contralateral aneurysms. In a series of 19 consecutive patients with bilateral aneurysms, Lynch and Andrade[6] reported that they succeeded in clipping or wrapping all contralateral aneurysms in 15 patients, including OA, anterior cerebral artery, ICA, and MCA locations.

In our anatomical study of human cadaver specimens, in which we used a standard frontotemporal surgical approach, we found that of the four most common sites for supratentorial aneurysms in the contralateral anterior circulation (excluding the midline anterior communicating artery), only the ICA termination can be exposed consistently in all specimens. Under optimum conditions, visualization of the contralateral ICA termination, and adequate proximal and distal vessel control should be possible in the majority of cases. However, in the clinical setting of acute SAH, factors such as brain swelling, hydrocephalus, or arachnoid adhesions may strongly affect this corridor of exposure. Case 14 in our series illustrates such circumstances; a contralateral approach to an ICA termination aneurysm was not attempted because of the degree of brain edema after SAH. By contrast, in Case 18, a contralateral ICA termination aneurysm was successfully clipped in a patient with no history of aneurysm rupture. Thus, although the corridor for exposure of contralateral ICA termination aneurysms may be reliable in idealized situations, individual anatomy and the clinical setting may strongly influence success with this approach.

The origin of the contralateral OA was exposed in $62 \%$ of dissections, and in all such cases this vessel arose from the medial surface of the CA. In cases in which the contralateral OA was visualized, we documented a range of 1 to $7 \mathrm{~mm}$ (mean $3.3 \mathrm{~mm}$ ) of the OA exposed after incision of the falciform ligament and mobilization of the optic nerve. Previously published anatomical studies[3,4] have noted that the origin of the OA is intracranial in 70 to $89 \%$ of cases and that it originates on the medial surface of the CA in 55 to $78 \%$ of cases, $[3,5]$ two conditions that are necessary for contralateral exposure.

Previous authors have proposed that for medially projecting OA aneurysms, the contralateral approach may be preferable, because it allows more direct access to the aneurysm neck and requires less manipulation of the overlying optic nerve.[13] The data from our microsurgical dissections reinforce the principle that the origin of the aneurysm neck from the medial surface of the supraclinoid CA may be critical for successful contralateral clipping of these aneurysms. The position of the OA origin and projection of the aneurysm neck should, therefore, be carefully assessed in the preoperative angiogram when considering a contralateral approach to OA aneurysms. Furthermore, because surgical exposure of the contralateral CA in the neck is probably not practical, intraoperative intraarterial balloon occlusion may be necessary in cases in which reliable proximal control is required. For these reasons, the contralateral exploration of OA aneurysms should be approached with caution and only performed in carefully selected patients, primarily those with medially projecting aneurysms. In our clinical series, the anatomy of the aneurysm permitted a contralateral approach in only one of three patients with OA aneurysms.

The origin of the PCoA is one of the most common sites for intracranial aneurysms, the majority of which project posteriorly and laterally with respect to the parent artery.[3] The contralateral PCoA origin could be visualized in only $50 \%$ of cases in our anatomical study. In all but one of such cases it was limited to the medial surface of the PCoA origin, as viewed through the corridor of the interoptic space 
or in the one case via the opticocarotid corridor. This observation correlates well with a previous study[3] documenting that the origin of the PCoA is medial or posteromedial in $4 \%$ and $44 \%$ of cases,

respectively. Because the medial surface of the PCoA origin is an uncommon projection for aneurysms at this site, the contralateral approach to PCoA aneurysms should be considered with caution. In selected cases, gentle retraction of the PCoA parent artery may allow visualization of the aneurysm neck, a technique that was used successfully in two cases in our series (Cases 1 and 6). Moreover, PCoA aneurysms may project posteromedially and inferiorly in some cases,[16] allowing for adequate visualization through the interoptic space. The PCoA aneurysms were clipped via the contralateral, interoptic space approach in four patients in our series (Cases 1, 7, 19, and 22), whereas in two patients brain edema related to acute $\mathrm{SAH}$ prevented a contralateral exposure.

The origin of the AChA is an unusual location for aneurysms.[15,17] However, localization or exposure of the contralateral AChA is important for the safe exploration of the supraclinoid CA segment via the contralateral approach. The origin of the AChA was exposed lateral to the optic chiasm, with lateral retraction of the distal ICA in seven $(44 \%)$ of 16 cases. Previous anatomical studies have described the AChA as originating from the posterior or posterolateral surface of the CA in the majority of cases (28\% and 66\%, respectively)[3] and lateral to the optic tracts and PCoA in essentially all cases.[10] Our study confirms these observations from the vantage point of the contralateral approach. In a defined fraction of cases, these anatomical features may allow visualization of the contralateral AChA lateral to the optic chiasm with retraction of the $\mathrm{CA}$ as we have described.

The MCA bifurcation was successfully exposed in $62 \%$ of specimens. Both Vajda, et al.,[13] and Lynch and Andrade[6] describe MCA bifurcation aneurysms that were inoperable from the contralateral side in their series, each suggesting that a long $\mathrm{M}_{1}$ segment may contribute to the inability to expose aneurysms at this site. In our study, we found a strong correlation between the length of the $\mathrm{M}_{1}$ segment and the ability to visualize the contralateral MCA bifurcation. We documented a length ranging from 7 to $26 \mathrm{~mm}$ (mean $13.5 \mathrm{~mm}$ ) for the $\mathrm{M}_{1}$ segment, which correlates well with the findings of previous authors (mean $15.7 \mathrm{~mm}$, Umanski, et al.;[12] and range 4.3-19.5 mm, mean $9.4 \mathrm{~mm}$, Gibo, et al.[2]). We also noted that the contralateral bifurcation could not be visualized if the $M_{1}$ segment was longer than $14 \mathrm{~mm}$. This findings may serve as a guideline when considering the contralateral approach to an MCA bifurcation aneurysm, because the length of the $\mathrm{M}_{1}$ segment can be approximated by measurements on the posteroanterior injection angiogram after correcting for magnification. However, exposure of the contralateral MCA bifurcation, although technically possible, requires significant retraction of both frontal lobes along with its inherent risks. Moreover, adequate visualization of the distal MCA branches is extremely difficult from the contralateral corridor of exposure. For these reasons, it is our opinion that a contralateral approach to MCA bifurcation aneurysms should be considered with extreme caution and only in carefully selected patients, with the majority of aneurysms in this location best treated from the ipsilateral side. In our series, no MCA bifurcation aneurysms were approached from the contralateral side.

A contralateral approach for supratentorial aneurysms of the anterior circulation remains an important consideration when planning the treatment of patients harboring multiple bilateral aneurysms. Our microsurgical anatomical study, in combination with our representative clinical experience with bilateral aneurysms, indicates that in a significant percentage of carefully selected patients, the successful surgical clipping of contralateral aneurysms is feasible and safe. Of course individual anatomy should be considered with respect to the guidelines we have presented, as well as the timing of surgery in relation 
to the SAH, insofar as tissue retraction and surgical exposure may be influenced by brain edema, amount of subarachnoid blood, or adhesion formation. Within the guidelines described here, the contralateral approach to supratentorial aneurysms should be considered in patients harboring bilateral lesions.

\section{Acknowledgment}

We thank Mr. Ronald Wade, Director, Maryland State Board of Anatomy, for assistance in the procurement of anatomical specimens and technical expertise in the vascular injections and preparation of the specimens.

\section{References}

1. Fox JL: Atlas of Neurosurgical Anatomy: The Pterional Perspective. New York: Springer-Verlag, 1989, pp 39-41

2. Gibo H, Carver CC, Rhoton AL Jr, et al: Microsurgical anatomy of the middle cerebral artery. J Neurosurg 54:151-169, 1981

3. Gibo H, Lenkey C, Rhoton AL Jr: Microsurgical anatomy of the supraclinoid portion of the internal carotid artery. J Neurosurg 55:560-574, 1981

4. Hayreh SS, Dass R: The ophthalmic artery. I. Origin and intra-cranial and intra-canalicular course. Br J Ophthalmol 46:65-98, 1962

5. Hayreh SS, Dass R: The ophthalmic artery. II. Intra-orbital course. Br J Ophthalmol 46:165-185, 1962

6. Lynch JC, Andrade R: Unilateral pterional approach to bilateral cerebral aneurysms. Surg Neurol 39:120-127, 1993

7. Milenkovic A, Gopic H, Antovic P, et al: Contralateral pterional approach to a carotid-ophthalmic aneurysm ruptured at surgery. Case report. J Neurosurg 57:823-825, 1982

8. Nakao S, Kikuchi H, Takahashi N: Successful clipping of carotid-ophthalmic aneurysms through a contralateral pterional approach. Report of two cases. J Neurosurg 54:532-536, 1981

9. Nishio S, Matsushima T, Fukui M, et al: Microsurgical anatomy around the origin of the ophthalmic artery with reference to contralateral pterional surgical approach to the carotid-ophthalmic aneurysm. Acta Neurochir 76:82-89, 1985

10. Rhoton AL Jr, Fujii K, Fradd B: Microsurgical anatomy of the anterior choroidal artery. Surg Neurol 12:171-187, 1979

11. Rinne J, Hernesniemi J, Puranen M, et al: Multiple intracranial aneurysms in a defined population: prospective angiographic and clinical study. Neurosurgery 35:803-808, 1994

12. Umanski F, Juarez SM, Dujovny M, et al: Microsurgical anatomy of the proximal segments of the middle cerebral artery. J Neurosurg 61:458-467, 1984

13. Vajda J, Juhász J, Pásztor E, et al: Contralateral approach to bilateral and ophthalmic anuerysms. Neurosurgery 22:662-668, 1988 
14. Yamada K, Hayakawa T, Oku Y, et al: Contralateral pterional approach for carotid-ophthalmic aneurysm: usefulness of high resolution metrizamide or blood computed tomographic cisternography. Neurosurgery 15:5-8, 1984

15. Yasargil M: Microneurosurgery. Stuttgart: Thieme, 1984, Vol 1, p 299

16. Yasargil M: Microneurosurgery. Stuttgart: Thieme, 1984, Vol 2, pp 46, 85, 116, 140

17. Yasargil MG, Yonas H, Gasser JC: Anterior choroidal artery aneurysms: their anatomy and surgical significance. Surg Neurol 9:129-138, 1978

Manuscript received October 25, 1996.

Accepted in final form February 6, 1997.

Address reprint requests to: Rafael J. Tamargo, M.D., Department of Neurosurgery, The Johns Hopkins Hospital, 600 North Wolfe Street, Meyer 7-113, Baltimore, Maryland 21287. 